\title{
HUBUNGAN ANTARA TIPE KEPRIBADIAN DENGAN INTERAKSI SOSIAL KARANG TARUNA DUKUH KLARISAN KELURAHAN TANDUK KECAMATAN AMPEL KABUPATEN BOYOLALI
}

\author{
Ika Puspitasari Putri ${ }^{1}$, Sapto Irawan $^{2}$ \\ ${ }^{1,2}$ Program Studi Bimbingan dan Konseling, Universitas Kristen Satya Wacana, Salatiga \\ Email : ika000.ppp@gmail.com ${ }^{1}$, sapto@staff.uksw.edu ${ }^{2}$
}

\begin{abstract}
Abstrak
Penelitian ini bertujuan untuk mengetahui Hubungan antara tipe kepribadian dengan interaksi sosial karang taruna Dukuh, Klarisan Kelurahan, Tanduk Kecamatan Ampel. Hipotesis yang diajukan dalam penelitian ini adalah Ada hubungan yang signifikan antaram Tipe Kepribadian dengan Interaksi Sosial anggota Karang Taruna Dukuh Klarisan, Kelurahan Tanduk, Kecamatan Ampel. Subjek dalam penelitian ini adalah anggota karang taruna Dukuh Klarisan, Kelurahan Tanduk, Kecamatan Ampel, yang berjumlah 80 orang. Pengumpulan data menggunakan skala Tipe kepribadian yang dikemukakan oleh Eysenck (Eysenck dan Wilson, 2003) dalam Eysenck Personality Questionare (EPQ) dengan jumlah item 36 pernyataan dan skala interaksi sosial oleh Soekanto (2013) dengan jumlah item 55 pernyataan. Pendekatan penelitian ini adalah kuantitatif korelasional dengan teknik korelasi Contingency Coefficient. Koefisien korelasi $r=0.525$ dengan signifikasi $0.000>0.05$, maka dapat dinyatakan bahwa ada hubungan yang signifikan antara tipe kepribadian dengan interaksi sosial karang taruna Dukuh, Klarisan Kelurahan, Tanduk Kecamatan Ampel. Dengan demikian hipotesis yang diajukan diterima.
\end{abstract}

Kata Kunci: Tipe Kepribadian, Interaksi Sosial, Karang Taruna.

\begin{abstract}
This study aims to determine the relationship between personality types and social interactions of the Dukuh, Klarisan Kelurahan, Tanduk Ampel sub-district. The hypothesis proposed in this study is that there is a significant relationship between the Personality Type and the Social Interaction of the members of the Karang Taruna in Klarisan, Tanduk Village, Ampel District. The subjects in this study were members of the Hamlet of Klarisan Hamlet, Tanduk Village, Ampel District, which numbered 80 people. Data collection uses a personality type scale proposed by Eysenck (Eysenck and Wilson, 2003) in the Eysenck Personality Questionnaire (EPQ) with the number of items 36 statements and the scale of social interaction by Soekanto (2013) with the number of items 55 statements. The approach of this study is quantitative correlational with the Contingency Coefficient correlation technique. Correlation coefficient $r=0.525$ with a significance of $0.000>0.05$, it can be stated that there is a significant relationship between personality types and social interactions between the youth organizations of Dukuh, Klarisan Kelurahan, Tanduk Ampel District. Thus the proposed hypothesis is accepted.
\end{abstract}

Keywords: Type of Personality, Social Interaction, Youth Organization 


\section{Pendahuluan}

Dalam kehidupan sehari-hari manusia tentu membutuhkan orang lain. Seperti halnya ketika kita hidup disebuah lingkungan perdesaan atau perkotaan yang mengharuskan kita untuk dapat berinteraksi dengan lingkungan sekitar maupun orang lain. Manusia sebagai makhluk sosial pada hakekatnya merupakan makhluk sosial yang sangat membutuhkan manusia yang lain untuk melangsungkan kehidupan. Bertemunya orang-perorang secara tidak langsung, tidak akan menghasilkan pergaulan hidup dalam suatu kelompok sosial. Pergaulan semacam itu baru akan terjadi apabila orang-orang atau kelompok-kelompok manusia bekerja sama, saling bicara dan seterusnya untuk mencapai tujuan bersama, mengadakan persaingan, pertikaian, dan lain sebagainya.

Namun setiap manusia itu berbeda-beda dan memiliki keunikan antara satu dan yang satunya. Misalnya kepribadian seseorang, kepribadian adalah keseluruhan cara individu untuk dapat berinteraksi dan komunikasi dengan orang lain. Menurut Jung (Alwison, 2004) kepribadian dibedakan menjadi dua yaitu kepridadian ekstrovert dan kepribadian introvert. Kepribadian ekstrovert biasnya mengambil keputusan dan sikap berdasarkan pengalaman orang lain, mereka cenderung ramah, terbuka, aktif dan suka bergaul. Kepribadian introvert dapat dikatakan sebagai sikap kesadaran seseorang yang selalu mengarah kepada dirinya sendiri, lebih menyukai kesendiri dari pada dengan orang lain.

Interaksi sosial seseorang dipengaruhi oleh banyak faktor antara lain faktor eksternal dan internal. Faktor internal itu sendiri tipe kepribadian yang dimiliki individu. Tipe kepribadian individu mempengaruhi interaksi sosial yang dilakukannya. Kepribadian inilah yang nantinya akan mempengaruhi bagaimana individu akan berinteraksi dengan sosialnya. Interaksi sosial sangatlah penting untuk dapat mengenali lingkunguan di sekitarnya, baik dalam lingkungan keluarga, tempat tinggal dan juga sekolah.

Tipe kepribadian tertentu mempunyai cara berinteraksi yang khas, dengan kata lain, kepribadian mempengaruhi cara individu dalam berinteraksi sosial. Dengan kepribadian yang terbuka maka individu akan mudah berinteraksi dengan orang-orang baru, sedangkan dengan kepribadian yang tertutup maka individu akan sulit untuk berinteraksi dengan orangorang baru (Arianty,2001)

Kurangnya interaksi sosial dalam bermasyarat itu akan menimbulkan suatu hal yang tidak bertujuan. Misalnya untuk meraih sebuah tujuan bersama diperlukan hubungan atau ikatan interaksi sosial yang baik, namun apabila sudah tidak ada interaksi sosial yang baik maka akan ada perbedaan atau gangguan-gangguan untuk mencapai tujuan itu.

Berdasarkan observasi dan juga wawancara dengan pengurus Karang Taruna di Dukuh Klarisan, Kelurahan Tanduk, Kecamatan Ampel, Kabupaten Boyolali menginformasikan bahwa anggota Karang Taruna berasal dari berbagai macam karakteristik dan sifat, banyak yang kurang mampu untuk bersosialisasi atau berinteraksi dengan orang lain dan orang yang ada disekitar lingkungan desa. Itu dapat dilihat banyaknya jumlah remaja hanya separuhnya aktif dalam kegiatan di desa. Kurangnya antusias remaja untuk berkumpul dan bersosialisasi. Menyebabkan masih banyak anggota yang lebih memilih diam di rumah daripada keluar mengikuti kegiatan yang ada di desa seperti bersih-bersih, kumpulan remaja dan juga ketika event-event tertentu. Masih sedikit remaja yang mampu untuk memberikan saran atau masukan ketika terjadinya sebuah diskusi kelompok.

Adapun tujuan dan manfaatnya sebagai berikut: untuk mengetahui signifikansi hubungan antara Tipe Kepribadian dengan Interaksi Sosial Anggota Karang Taruna Dukuh Klarisan, Kelurahan Tanduk, Kecamatan Ampel, Kabupaten Boyolali.Manfaat penelitian ini diharapkan dapat bermanfaat sebagai bahan masukan kepada Karang Taruna Dukuh Klarisan, Kelurahan Tanduk, Kecamatan Ampel, Kabupaten Boyolali. Untuk memahami karakter individu setiap anggota yang berguna sebagai pengembangan diri.

Interaksi sosial Soekanto (2013) mendefinisikan interaksi sosial sebagai hubungan sosial yang dinamis, dengan kelompok. Selain itu, interaksi sosial juga didefinisikan sebagai suatu hubungan antara dua orang atau lebih individu, dimana kelakuan individu 
mempengaruhi atau mengubah individu lain. Menurut Monks dkk (2002) ada beberapa faktor yang dapat mempengaruhi interaksi sosial yaitu: jenis kelamin, besaran suatu kelompok, keinginan untuk memiliki status, interaksi orang tua, pendidikan dan kepribadian. Soekanto (2013) berpendapat bahwa suatu interaksi sosial tidak akan mungkin terjadi apabila tidak memenuhi dua syarat, yaitu (a) kontak sosial meliputi kerjasama, interaksi, bertemu langsung dan berhadapan, adanya perantara pihak lain maupun alat bantu. (b) komunikasi meliputi menggunakan suara dan bahasa tubuh

Tipe kepribadian menurut Eysenck (Alwison 2004) Kepribadian adalah pola tingkah laku yang sudah terjadi pada individu, yang dapat ditentukan oleh faktor keturunan dan lingkungan. Pola tingkah laku itu berasal dan berkembang melalui empat sektor utama dimana pola-pola prilaku ini diatur: Sektor kognitif (intelligence) sektor kognatif (character) sektor afektif (tremprament) sektor sikomotorik (constitution) (Allport). Berdasarkan uraian para ahli dapat disimpulkan bahwa kepribadian memiliki arti pola tingkah laku yang terjadi pada individu yang dapat ditentukan oleh keturunan dan lingkungan sosial.

Karakteristik kepribadian ekstrovert dan introvert saling berlawanan namun salah satu diantaranya lebih dominan dan disadari, sedangkan yang lain kurang dominan dan tidak disadari. Jung (Suryabrata, 2015). Selain dikemukakan Jung (Suryabrata, 2015) teori mengenai kepribadian ekstrovert dan introvert juga dikemukakan oleh Eysenck. Eysenck membedakan kepribadian menjadi 2 tipe kepribadian yaitu, tipe ekstrovert dan tipe introvert, untuk perbadaan dalam berinteraksi sosial dan prilaku sosial. Dia juga mengemukakan bahwa tipe kepribadian ekstrovert-introvert menggambarkan keunikan individu dalam bertingkah laku terhadap suatu stimulus sebagai perwujutan karakter, tempramen, fisik dan intelektual individu dalam menyesuaikan diri dengan lingkungan.

Pengertian Kepribadian Ekstrovert menurut Jung (Suryabrata, 2015) orang Ekstrovert di pengaruhi oleh dunia objective di luar dirinya. Lebih tertuju pada pemikiran, perasaan yang di dasari dan timbul dari lingkungan. Baik lingkungan sosial atau non sosial. Eysenck (Santrock, 2007) mengemukakan bahwa seseorang yang memiliki tiap kecenderungan tipe Ekstrovert akan memiliki ciri sebagai berikut: mereka tergolong orang yang suka bergaul, menyukai keramaian, selalu membutuhkan orang lain untuk di ajak berbicara dan menyukai segala cara bentuk kerja sama. Mereka selalu mengambil kesempatan yang datang pada dirinya.

Pengertian Kepribadian Introvert menurut Jung (Alwison, 2004), orang yang introvert terutama dipengaruhi oleh dunia subjektif, yaitu dunia dalam dirinya sendiri. Lebih tertuju ke dalam pikiran dan perasaan, penyesuaiannya dengan lingkungan luar kurang baik, jiwanya tertutup, tidak mudah bergaul, kurang pintar untuk berkomunukasi dengan orang lain. Menurut Eysenck (Santrock 2007) Tipe kepribadian Introvert, mereka lebih memilih untuk menarik diri lingkungan, mereka biasanya tertutup, tidak suka memperhatikan orang lain dan pendiam.

\section{Metode}

Jenis penelitian ini adalah penelitian korelasional. Menurut soesilo (2018) penelitian korelasional merupakan suatu penelitian yang bertujuan untuk menyelidiki (membuktikan) sejauh mana keterkaitan atau keeratan hubungan antara suatu variabel dengan satu atau lebih variabel lain. Tujuan penelitian ini adalah untuk menentukan ada tidaknya korelasi antara dua variabel.

Penelitian ini dilakukan di Dukuh Klarisan, Kelurahan Tanduk, Kecamatan Ampel. Adapun waktu penelitian ini dilakukan kurang lebih 3 bulan yaitu bulan yaitu terhitung bulan desember 2018 - Februari 2019. Teknik pengambilan sampel pada penlitian ini menggunakan total sampling. Total sampling adalah teknik pengambilan sampel dimana jumlah sampel sama dengan populasi. Sampel dalam penelitian ini adalah semua anggota Karang Taruna yang berjumlah 80 .

Metode pengumpulan data yang digunakan dalam penelitian ini adalah dengan menggunakan skala, terdiri dari dua jenis yaitu, skala tipe kepribadian dan skala interaksi 
sosial Skala tipe kepribadian yang digunakan dalam penelitian ini merupakan skala yang berupa pernyataan-pernyataanya disusun berdasarkan dari aspek-aspek menurut yaitu: (EPQ Eysenck's Personality Questionnare) Activity, Sociability, Risk-taking, Impulsiveness, Expressiveness, Reflectiveness, Responsibility dan di adaptasi dari Yuliana Mita (2009) . Skala Interaksi Sosial penulis buat berdasarkan adaptasi dari Dian Pranacitra (2010), berdasarkan aspek- aspek dari Soekanto (2013) yaitu Kontak Sosial dan Komunikasi.

Untuk menguji hipotesis dalam penelitian ini teknik analisis data yang digunakan adalah: korelasi Contingency Coefficient, bertujuan untuk mengetahui ada atau tidak ada hubungan (korelasi) antara tipe kepribadian dengan interaksi sosial anggota karang taruna Dukuh Klarisan, Desa Tanduk, Kecamatan Ampel. Pengujian korelasi ini menggunakan dibantu dengan program SPSS For Windows versi 20.

\section{Hasil dan Pembahasan}

Data yang diperoleh dari 80 responden dan telah dianalisis menggunakan teknik analisis Contingency Coefficient. Diketahui hasil dengan nilai $r=0.525$ dengan koefisien signifikansi $0.000<0.05$, dengan demikian ada hubungan yang signifikan antara tipe kepribadian dengan interaksi sosial Karang Taruna Dukuh Klarisan, Desa Tanduk, Kecamatan Ampel, Kabupaten Boyolali dengan tingkat hubungan kuat.

Selanjutnya untuk mengetahui hubungan Tipe Kepribadian dan Interaksi sosial menggunakan Contingency Coefficient didapat hasil

Tabel 1. Data Contingency Coefficient

\begin{tabular}{c|c|c|c|c|c}
\hline Tipe & \multirow{4}{|c|}{ SOSIAL } & Total \\
Kepribadian & Tinggi & Cukup & Sedang & Renda & \\
& & tinggi & 4 & $\mathrm{~h}$ & 49 \\
Ekstrovet & 20 & 25 & & 0 & \\
Introvert & 1 & 11 & 15 & 4 & 31 \\
Total & 21 & 36 & 19 & 4 & 80 \\
\hline
\end{tabular}

Dapat diketahui bahwa untuk tipe kepribadian ekstrovert dan introvert dengan interaksi sosial tinggi, interaksi sosial cukup tinggi, interaksi sosial sedang, interaksi sosial rendah. Sebanyak 49 orang memiliki tipe kepribadian ekstrovert, 20 orang interaksi sosial tinggi, 20 orang interaksi sosial cukup tinggi, 4 orang interaksi sosial sedang dan untuk tingkat interaksi sosial sangat rendah 0 . Sebanyak 31 orang memiliki tipe kepribadian introvert, untuk 1 orang interaksi sosial tinggi, 11 interaksi sosial cukup tinggi, 15 orang interaksi sosial sedang, 4 orang interaksi sosial rendah.

Dari hasil SPSS Contingency Coefficient dikatakan bahwa anggota Karang Taruna Dukuh Klarisan, Desa Tanduk, Kecamatan Ampel, Kabupaten Boyolali dominan memiliki tipe kepribadian ekstrovert. Tipe kepribadian ekstrovert mengarahkan seseorang pada dunia luar yang objektif, yaitu dunia di luar dirinya. Ciri-ciri orang ekstrovert adalah ramah, menarik, mudah bergaul, mempunyai hubungan interaksi sosial yang baik dan cenderung memberikan penilaian yang positif terhadap orang lain (Latifah, 2012). Ketika seorang memiliki tipe kepribadian ekstrovert maka tingkat interaksi sosialnya sangat tinggi, hal ini bisa disebabkan karena mereka mempunyai karakteristik mudah bergaul dan terbuka sehingga ia akan lebih memahami pesan yang disampaikan dalam komunikasi. Dia selalu berorientasi pada objek sehingga mudah baginya untuk menangkap isi komunikasi yang hendak disampaikan oleh orang lain.

Sebaliknya, sikap introvert mengarahkan pada dunia dalam subjektif, tindakan dan pemikirannya bersifat subjektif. Orang introvert akan mengalami gangguan atau hambatan dalam komunikasi maupun melakukan kontak sosial, karena individu dengan karakteristik tersebut suka menyendiri dan mengabaikan faktor eksternal yang penting. Ketika seorang 
memiliki tipe kepribadian yang cenderung introvert maka tingkat interaksi sosialnya sangat rendah, hal ini bisa disebabkan karena mereka cenderung tertutup dan menyukai kegiatankegiatan yang dilakukan seorang diri karena mereka sulit untuk mengemukakan pendapat kepada orang lain dan cenderung menarik diri dari lingkungan sosial.

\section{Simpulan dan Saran}

Berdasarkan analisis data dapat ditarik kesimpulan bahwa hipotesis yang menyatakan ada hubungan yang signifikan antara tipe kepribadian dan interaksi sosial anggota karang taruna Dukuh Klarisan, Desa Tanduk, Kecamatan Ampel, Kabupaten Boyolali diterima. Ini berarti semakin ekstrovert tipe kepribadian seseorang, maka akan semakin tinggi interaksi sosialnya. Begitu pula sebaliknya, semakin introvert tipe kepribadian seseorang, maka semakin rendah interaksi sosialnya. Hal ini dapat dilihat dari nilai koefisiensi korelasi $r=$ 0.525 dengan signifikansi $0,000(p<0,05)$.

Saran bagi anggota Karang Taruna dalam hubungan dengan interaksi sosial, anggota karang taruna yang memiliki interaksi sosial tinggi disarankan untuk tetap dapat mempertahankan dan mengembangkan untuk lebih baik lagi. Untuk yang interaksi sosialnya rendah diharapkan dapat meningkatkan interaksi sosial, hal ini agar lebih baik dan sesuai dengan tujuan interaksi sosial. Hal itu bisa di capai dengan cara mengikuti kegiatan yang ada di desa, misalnya dengan kumpulaan remaja yang di adakan rutin setiap bulan. Kegiatan seperti kumpulan ini sangat baik di lakukan karena bisa mempererat antar anggota satu sama lain. Interaksi akan semakin sering terjadi bila kegiatan kumpulan diadakan, karena anggota akan bertemu secara langsung dan berkomunikasi. Cara lain yang bisa di gunakan adalah sering diadakannya kegiatan bersih desa atau kerja bakti setiap minggu untuk mempererat hubungan silaturahmi antar anggota dan meningkatkan kekompakan antar anggota. Liburan bersama juga bisa di lakukan, hal ini bertujuan agar kekompakan antar anggota semakin meningkat, misalnya dengan outbond bersama. Anggota yang introvet juga akan melakukan kegiatan bersama teman yang lain. Sehingga semua anggota menjadi satu dan kompak.

\section{Daftar Pustaka}

Alwison. 2004 Psikologi Kepribadian Edisi 10.UMM.press.

Arianty, D. 2001 Hubungan Antara Tipe Kepribadian Ekstrovert-Introvert Dengan Ketrampilan Komunikasi Intrapersonal Pada Mahasiswa. Skripsi Tidak Diterbitkan. Fakultas Psikologi Sanata Dharma.

Eysenck, H.J., and Wilson, G. 2003. Mengenal Diri Pribadi. Jakarta: ANS Sungguh Bersaudara. Goldstein, Harootunian, \& Conoley, et al. (2003)

Feni, Latifah. 2012. Hubungan Antara Dukungan Sosial Dengan Penyesuaian Diri Remaja Panti Asuhan. Jurnal Psikologi Pitutur. Volume 1 No 2. Kudus : Universitas Muria Kudus

Monks, F.J. (2002) Psikologi Perkembangan: Pengantar Dalam Berbagai Bagiannya. Cet. 14.: Yogyakarta: Gajah Mada University Press.

Peraturan Metri Sosial Republik Indonesia Noer 23 Tahun 2013 tentang Pemberdayaan Karang Taruna

Pranacitra, D. 2010. Hubungan Antara Tipe Kepribadian Dengan Kecenderungan Melakukan Interaksi Sosial Positif Pada Remaja. Fakultas Psikologi Sanata Dharma. 
Soesilo, Tritjahjo Danny.2018. Penelitian Inferensial dalam Bidang Pendidikan. Salatiga : Satya Wacana University Press

Soekanto, Soerjono. (2013). Sosiologi Suatu Pengantar( Edisi Revisi). Jakarta: Raja Grafindo Persada.

Sugiono. 2012 Statistik Penelitian. Bandung: Penerbit Alfabert

Suryabrata,S.2015 Psikologi Pendidikan, Jakarta: PT Rajagrafindo Persada.

Yuliana, M. 2009. Hubungan Antara Tipe Kepribadian Ektrovert dan introvert dengan orientasi Keterampilan Komunikasi Distributor Multi Level Marketing Tianshi. Jurnal Psikologi. Vol 2 :USD 